\title{
Nystatin Profile on Candida Species in HIV/AIDS Patients with Oral Candidiasis: A Phenomenology Study
}

\author{
Dwi Murtiastutik* (D), Cut Shelma Maharani, Rahmadewi and Muhammad \\ Yulianto Listiawan
}

Department of Dermatology and Venereology, Faculty of Medicine, Universitas Airlangga, Dr. Soetomo General Hospital, Surabaya - 60285, Indonesia.

\begin{abstract}
Oral candidiasis is the main symptom that often appears in patients with Human Immunodeficiency Virus (HIV) / Acquired Immune Syndrome (AIDS). Recent studies reported that some bacteria causing oral candidiasis are resistant to antifungal drugs. Describing nystatin profile against candida species in HIV / AIDS patients with oral candidiasis. Twenty-nine subjects were divided into 2 groups based on sex ( 23 male subjects and 6 female subjects). Subjects carried out tissue culture procedure and were tested for sensitivity to fluconazole and nystatin. The analysis was conducted by comparing sex and type of infecting bacteria. Statistical analysis used chi-square test, fisher, or ANOVA with $95 \% \mathrm{Cl}$ with $p<0.05$. The average age of male and female subjects was $43.15 \pm 3.67$ years and $40.02 \pm 10.23$ years, respectively, with age range of 18-65 years. Recurrent oral candidiasis in male and female patients was $65.22 \%$ and $83.33 \%$, respectively $(p=0.079)$. Subjects were resistant to fluconazole as much as $77.50 \%$ in men and $61.54 \%$ in women $(p=0.823)$. On the other hand, subjects sensitive to nystatin were $92.50 \%$ in men and $92.31 \%$ in women ( $p=0.167)$. Fluconazole was resistant to Candida albicans $(68.00 \%)$ and non-Candida albicans $(78.57 \%)(p=0.048)$, while nystatin was sensitive to Candida albicans $(92.00 \%)$ and non-Candida albicans $(92.86 \%)(p=0.791)$. Most subjects were resistant to fluconazole, while the majority of subjects were sensitive to nystatin.
\end{abstract}

Keywords: Nystatin, fluconazole, oral candidiasis, Candida albicans, HIV/AIDS.

*Correspondence: dwimurtiastutik@yahoo.co.id; (+6231) 5020251

(Received: 29 July 2019; accepted: 11 October 2019)

Abbreviation: HIV: human immunodeficiency virus; CA=Candida albicans; NCA=Non-candida albicans; AIDS: acquired immunodeficiency syndrome; WHO: world health organization; ARV: antiretrovirals; and SDA: Sabouraud Dextrose Agar.

Citation: Dwi Murtiastutik, Cut Shelma Maharani, Rahmadewi and Muhammad Yulianto Listiawan, Nystatin Profile on Candida Species in HIV/AIDS Patients with Oral Candidiasis: A Phenomenology Study, J Pure Appl Microbiol., 2019; 13(4):2013-2019. https://doi.org/10.22207/JPAM.13.4.12

(C) The Author(s) 2019. Open Access. This article is distributed under the terms of the Creative Commons Attribution 4.0 International License which permits unrestricted use, sharing, distribution, and reproduction in any medium, provided you give appropriate credit to the original author(s) and the source, provide a link to the Creative Commons license, and indicate if changes were made. 


\section{INTRODUCTION}

Oral candidiasis is one of the first clinical signs of AIDS found in $50 \%$ to $95 \%$ of HIV/AIDS patients. The condition is mostly caused by Candida albicans, which number is around 2-69.1\% found in adult's oral cavity ${ }^{1,2}$. Candida albicans is not the only species causing candidiasis, but also other species including Candida glabrata, Candida krusei, Candida tropicalis, Candida parapsilosis and Candida dubliniensis. Candida species is a commensal microorganism found in oral mucosa. However, this species becomes a predisposition factor causing oral candidiasis ${ }^{3,4}$. Early treatment of oral candidiasis, according to WHO, includes administration of topical antifungal agents, such as nystatin, amphotericin B, miconazole, and clotrimazole. Those agents can be given in oral candidiasis case without complication ${ }^{2,5}$.

In Indonesia, nystatin is an effective and affordable choice of antifungal for oral candidiasis ${ }^{3}$. The available doses of nystatin are $100.000 \mathrm{U} / \mathrm{mL}$, and $400.000-600.000 \mathrm{U} / \mathrm{mL}$ for adults for 4 times a day for $7-14$ days $^{6,5}$. In 2017, there were 261 out of 1020 patients with HIV/AIDS treated in Dr. Soetomo General Hospital, Surabaya, Indonesia, who experienced oral candidiasis. The number increased to 273 patients in 2018. From June July 2018 , there were 20 oral candidiasis patients treated with oral nystatin, but $30 \%$ of which returned to the hospital with the similar case.

Based on the above explanation, the authors conducted an in vitro test to measure nystatin resistance in oral candidiasis patients with HIV/AIDS.

\section{METHODS}

The subjects of this research were HIV/ AIDS patients treated in Dr. Soetomo General Hospital Surabaya, Indonesia. The inclusion criteria were: HIV/AIDS patients diagnosed with rapid test/3 HIV testing methods ${ }^{7,8}$, having diagnosed with oral candidiasis by clinical examination and $10-20 \% \mathrm{KOH}_{\text {test }}{ }^{9,10}$, and male or female patients aged $>18$ years. This study excluded subjects taking antifungal drugs in 2 weeks before test, and no colony growth found on culture examination with candida Sabouraud Dextrose Agar (SDA). The subjects must fulfill the informed consent.

This study employed an observational descriptive design carried out from August 2018 to
February 2019. The process of culture extraction was conducted in Dr. Soetomo General Hospital, Surabaya, Indonesia, and followed by culture examination that was carried out in Surabaya Health Laboratory, Surabaya, Indonesia. There were 29 patients who were consecutively sampled for the subjects in this research (Fig. 1). We also obtained 53 Candida isolates. The study protocol was in accordance with ethical procedure (0231/ KEPK/IV/2018).

We first examined the subject's culture ${ }^{9,10}$ that was taken from oral tissue swab. The positive Candida was grown in SDA at $37^{\circ} \mathrm{C}$ for 48 hours ${ }^{11}$. We used CHROMagar Candida (CHROMagar Candida, France) as the SDA medium. The growing Candida specimen were identified using cornmeal agar and tween 80 that were incubated at 42$45^{\circ} \mathrm{C}^{12,13}$. We also conducted carbohydrate test to identify Candida species ${ }^{14}$. Furthermore, we conducted resistance test using disc diffusion method on Mueller Hinton agar with 2\% glucose and methylen blue. The isolate of Candida species was implanted on the agar, then a paper disk containing nystatin or fluzonazole was placed on top of it. We made a 24-48-hour-observation to look for an inhibition zone around the paper disc. The diameter of inhibition zone was measured using caliper (Rosco Diagnostica, Taastrup, Denmark). We interpreted the inhibition zone diameter using $\mathrm{CLSI}^{15}$. This study used nystatin with a dose of 100,000 UI/ml (pharma chemistry Ltd, Bekasi, Indonesia) and fluconazole at a dose of 2 $\mathrm{mg} / \mathrm{ml}$ (pharma chemistry Ltd, Bekasi, Indonesia)

We assessed demographic and clinical data of patients. The collected data were then processed using IBM SPSS Statistics software version 23.0 (IBM Corp., Armonk, NY, USA). The statistical analysis used chi-square, fisher, or ANOVA with $95 \% \mathrm{Cl}(\mathrm{p}<0.05)$.

\section{RESULTS}

Twenty-nine patients were divided into two groups based on their sex that consisted of 23 male subjects and 6 female subjects. The average age of male and female patients was $43.15 \pm$ 3.67 years and $40.02 \pm 10.23$, respectively. They were divided into several age groups, where most subjects were found in the age range of $36-45$ years ( 8 subjects; $27.59 \%$ ), and followed by age group of $56-65$ years ( 7 subjects; $24.13 \%$ ). Most 
subjects had high school education background (48.27\%), and unemployed (12 subjects; $41.37 \%)$ (Table 1). Most patients were Javanese (48.28\%), and followed by Madurese (44.83\%).

The subject's clinical condition was as follows: 27 subjects $(93.10 \%)$ had lesions on the tongue, 1 subject $(3.45 \%)$ in the mucous membrane, and 1 subject (3.45\%) in the corner of the lips (Figure 2). Most subjects were recurrent oral candidiasis patients ( male $=65.22 \%$ and female $=83.33 \%)(p=0.079)$. Some subjects had a history of systematic antifungal treatment ( male $=17.39 \%$ and female $=16.67 \%$ ) and topical antifungal (male $=34.78 \%$ male and female $=$ $50.00 \%$ ), with $p=0.002$. Most subjects used antiretroviral (ARV) as much as $86.96 \%$ in men and $10.34 \%$ in women $(p=0.518$; Table 1$)$.

Table 1. Demographic and Clinic Characteristics of patient Gender

\begin{tabular}{lccc}
\hline \multirow{2}{*}{ Variable } & \multicolumn{2}{c}{ Sex } & $p$ \\
\cline { 2 - 3 } & Male $(n=23)$ & Female $(n=6)$ & \\
\hline Age (mean \pm SD) & $43.15 \pm 3.67$ & $40.02 \pm 10.23$ & - \\
Education (\%) & & & - \\
Not attending school & $2(8.70)$ & $2(33.33)$ & \\
Junior high school & $7(30.44)$ & $1(16.67)$ & \\
Senior high school & $11(47.83)$ & $3(50.00)$ & \\
Undergraduate/Diploma & $3(13.04)$ & $0(0.00)$ & \\
Ethnic (\%) & $10(43.48)$ & $4(66.67)$ & \\
Java & $11(47.83)$ & $2(33.33)$ & \\
Madura & $2(8.70)$ & $0(0.00)$ & \\
Other & $15(65.22)$ & $5(83.33)$ & 0.079 \\
Oral candidiasis (\%) & $8(34.78)$ & $1(16.67)$ & \\
Recurrent & & & \\
First infection & $4(17.39)$ & $1(16.67)$ & $0.002^{*}$ \\
Treatment history (\%) & $8(34.78)$ & $3(50.00)$ & \\
Systemic antifungal & $20(86.96)$ & $3(50.00)$ & 0.518 \\
Topical antifungal & & & \\
ARV treatment (\%) & & & \\
\hline
\end{tabular}

$\mathrm{SD}=$ standard deviation; $\mathrm{ARV}=$ antiretroviral; *significant 0.05

Table 2. Comparison of culture results on male and female subjects

\begin{tabular}{lccc}
\hline Variable & \multicolumn{2}{c}{ Sex } & $p$ \\
\cline { 2 - 3 } & $\begin{array}{c}\text { Male } \\
(\mathrm{n}=40)\end{array}$ & $\begin{array}{c}\text { Female } \\
(\mathrm{n}=13)\end{array}$ & \\
\hline $\begin{array}{l}\text { Bacterium (\%) } \\
\text { Candida albicans }\end{array}$ & $18(45.00)$ & $7(53.85)$ & $0.035^{*}$ \\
$\begin{array}{l}\text { Non-Candida } \\
\text { albicans }\end{array}$ & $22(55.00)$ & $6(46.15)$ & \\
$\begin{array}{l}\text { Fluconazole (\%) } \\
\text { Sensitive }\end{array}$ & $9(22.50)$ & $5(38.46)$ & 0.823 \\
Resistance & $31(77.50)$ & $8(61.54)$ & \\
$\begin{array}{l}\text { Nystatin (\%) } \\
\text { Sensitive }\end{array}$ & $37(92.50)$ & $12(92.31)$ & 0.167 \\
Resistance & $3(7.50)$ & $1(7.69)$ & \\
& & &
\end{tabular}

Table 3. Comparison of fluconazole and nystatin sensitivity tests in the Candida albicans and noncandida albicans groups

\begin{tabular}{|c|c|c|c|}
\hline \multirow[t]{2}{*}{ Variable } & \multicolumn{2}{|c|}{ Bacterium } & \multirow[t]{2}{*}{$p$} \\
\hline & $C A(n=25)$ & $\operatorname{NCA}(n=28)$ & \\
\hline \multicolumn{4}{|c|}{ Fluconazole (\%) } \\
\hline Sensitive & $8(32.00)$ & $6(21.43)$ & $0.048^{*}$ \\
\hline Resistance & $17(68.00)$ & $22(78.57)$ & \\
\hline \multicolumn{4}{|l|}{ Nystatin (\%) } \\
\hline Sensitive & $23(92.00)$ & $26(92.86)$ & 0.791 \\
\hline Resistance & $2(8.00)$ & $2(7.14)$ & \\
\hline
\end{tabular}

$\mathrm{CA}=$ Candida albicans; NCA=Non-candida albicans; *significant 0.05

\footnotetext{
*significant 0.05
} 


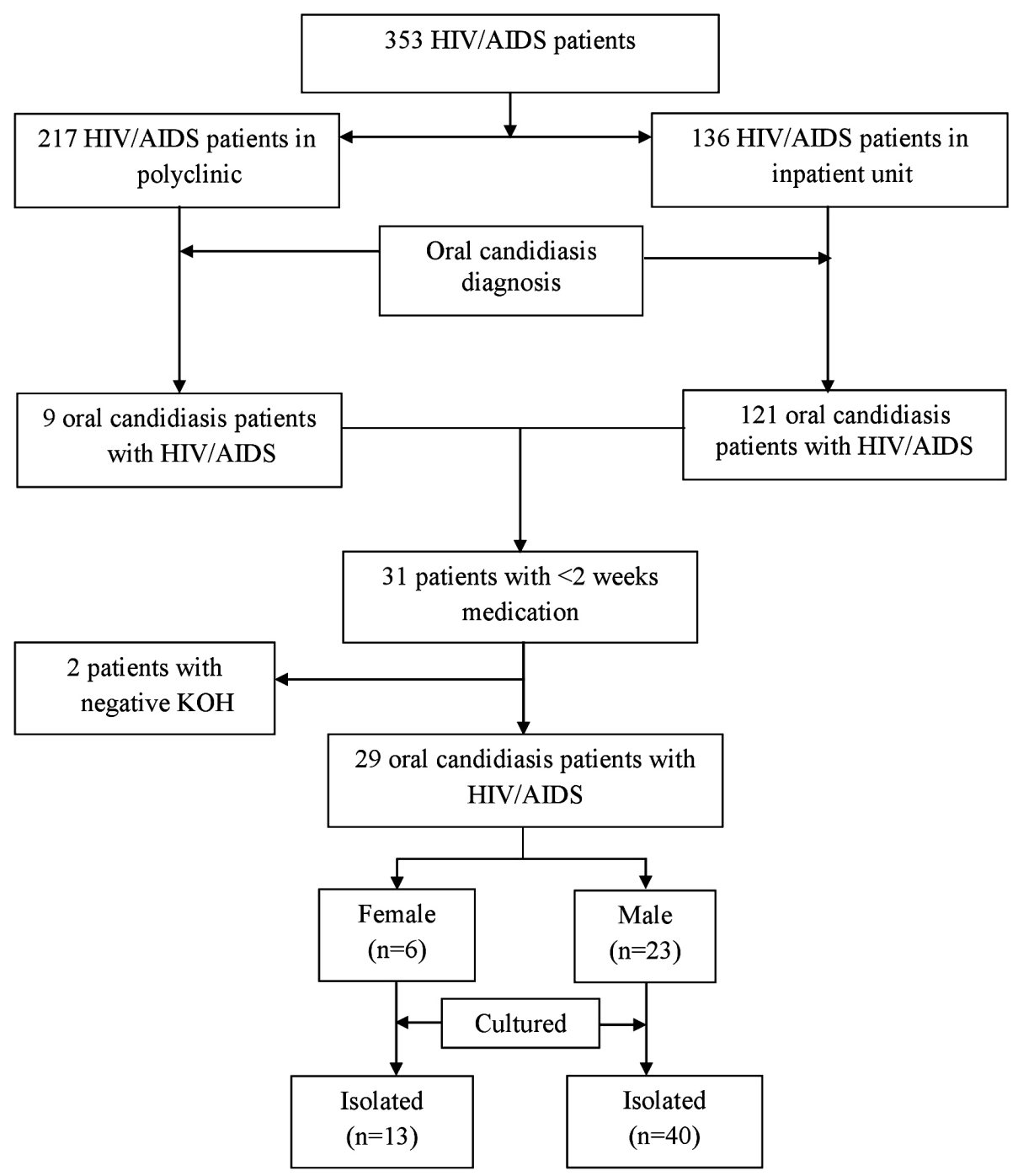

Fig. 1. Flowchart Diagram of Subject Sampling

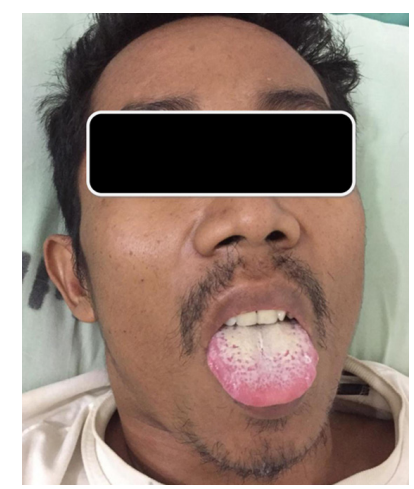

Fig. 2. Clinical picture of the subject on the first day of hospital admission
Culture comparison based on the sex found that most subjects were infected with nonCandida albicans bacteria as much as $55.00 \%$ in male subjects, while most female subjects were infected with Candida albicans bacteria as much as $53.85 \%(p=0.035)$. Most subjects were resistant to fluconazole as much as $77.50 \%$ in men and $61.54 \%$ in women ( $p=0.823$ ). The majority of subjects were sensitive to nystatin as much as $92.50 \%$ in men and $92.31 \%$ in women ( $p=0.167$; Table 2 ).

Most candida albicans bacteria were resistant to fluconazole (68.00\%), and most nonCandida albicans bacteria were also resistant to 
fluconazole (78.57\%) ( $p=0.048)$. Most Candida albicans bacteria were sensitive to nystatin drugs $(92.00 \%)$, while non-candida albicans bacteria were mostly sensitive to nystatin drugs as much as $92.86 \%(p=0.791$; Table 3$)$.

\section{DISCUSSION}

The demographic data of this research included age, educational level and occupation. The highest age range was found in the adult group (63\%). According to the data of Directorate General PPM \& PL of the Ministry of Health in 2016, there were more than $50 \%$ HIV/AIDS patients were young adults and productive age groups with age group of 25-49 years old ${ }^{16}$. The finding of this study supported that adults included in productive and sexually active groups were more likely to engage in unprotected sexual behavior that was prone to HIV transmission ${ }^{17}$.

HIV/AIDS infection is a disease that has a huge social impact. Ninety percent of HIV/AIDS patients are likely to have oral cavity diseases that will have impact on the life quality, including occupational sector. This study found that $45 \%$ of the subjects were unemployed, and 9 subjects (45\%) were high school graduates. HIV/ AIDS patients with a low educational and socioeconomic background have a bad oral health that makes them prone to oral cavity diseases ${ }^{18}$.

This study found that most patients were infected HIV due to heterosexual behavior (65\%). This finding reflected the general condition of HIV/AIDS in East Java, in which the virus is mostly transmitted through heterosexual behavior $(69.6 \%)$, followed by narcotics $(21.9 \%)^{19}$. All patients in this study had white patches in their oral cavity, and being diagnosed with pseudomembranous oral candidiasis. This finding was consistent with a study conducted in India in 2013, in which pseudomembranous candidiasis was found in $72 \%$ of the subjects ${ }^{20}$. The ARV administration to HIV/AIDS patients could significantly reduce oral candidiasis. Some patients in this study previously had ARV therapy, while the new HIV/AIDS patients had not received the therapy yet ${ }^{21,22}$. Fungal infection was still found in most patients with antifungal therapy history, both systemic and topical ${ }^{23}$.

A disc diffusion method was conducted to measure sensitivity of all Candida species to nystatin. The results of sensitivity test were in the form of inhibition zone diameter. The criteria of susceptibility and resistance to antifungal agents were determined according to the interpretation of inhibition zone diameter for fungi by Rosco Diagnostica Company ${ }^{24}$. This study found that neither Candida albicans nor Candida non-albicans species that resisted to nystatin. Nystatin currently becomes the primary therapy for oral candidiasis in patients with HIV/AIDS.

The resistance against nystatin was divided into two groups, namely intrinsic and extrinsic sensitivity. The extrinsic sensitivity shows a change in sensitivity pattern of Candida species, from sensitive to resistance against antifungal therapy. On the other hand, intrinsic sensitivity has occurred early on antifungal therapy. This study found some intrinsic sensitivities in a form of infection caused by Candida krusei, which occurred in $8 \%$ of subjects ${ }^{25}$.

Some literatures stated that nystatin resistance is very minimum, but the therapy has side effects and toxicity. Nystatin generally works by distracting fungal cytoplasmic membrane and interacting with ergosterol. Ergosterol is important to maintain integrity and function of the enzymes of fungal membrane. Nystatin produces holes in cell membrane that becomes a way out for potassium ion and magnesium cellular components. This causes damages in proton gradient of cell membrane that leads to fungal cell death. Nystatin has a high binding capacity to ergosterol and low binding capacity to 3 hydroxy or oxysterol, such as fecosterol and episterol that becomes an important reason for nystatin resistance ${ }^{26}$.

Although there is an increased in nystatin resistance, this remains a rare occurrence in fungal pathogenic isolates since nystatin could not be used for systemic fungal infection. Therefore, the indications are not as much as the azole group. The incident of nystatin-resistant strains may be largely not considered. Most fungal species are considered susceptible to nystatin. However, some of which intrinsically less susceptible to this antifungal agent, such as Candida glabrata, Scedosporium prolificans and Aspergillus terreus. Some species are also more susceptible to nystatin resistance, including Candida lusitaniae, Candida guilliermondii and Candida krusei $i^{27,25}$. 
Factors such as recurrent oral candidiasis and history of antifungal usage are considered to cause differences of Candida species. Those factors are thought to be a predisposing factor that changes the type of Candida into Candida nonalbicans. This may occur in patients with recurrent oral candidiasis as they are also exposed to antifungal medication thus supports the previous hypothesis. The characteristics of an antifungal drug are also factors that play a role in a difficultto-treat infection. Fungistatic drugs will further encourage the formation of resistance compared to fungicidal drugs. Absorption, distribution and metabolism of a drug also contribute to the overall effectiveness of treatment based on the location of an infection. Antifungal drug dosages, including quantity, frequency, administration schedule and cumulative doses, can also play a role in treating a fungal infection. The administration of antifungal medication along with other prescription can also change the effectiveness of antifungal drugs. In addition, in the course of advanced HIV/AIDS, extensive fungal colonization was also found ${ }^{27}$.

This study found a change in the spectrum causing oral candidiasis, since Candida albicans species were mostly found, while the number of Candida non-albicans was increasing.

\section{CONCLUSION}

In the invitro test, no Candida isolate was found to be resistant to nystatin. Therefore, oral nystatin is still effectively used as a standard therapy for HIV/AIDS patients with oral candidiasis.

\section{ACKNOWLEDGEMENTS}

Special thanks to Hastika Saraswati, MD who has assisted in our paper translate and Bernadya Yogatri Anjuwita Saputri, MD who helped us in the research. In addition, we would like to thank the Surabaya Health Laboratory, Indonesia, for helping us to carry out fluconazole resistance tests.

\section{CONFLICTS OF INTEREST}

The authors declare that there is no conflict of interest.

\section{AUTHORS' CONTRIBUTION}

DM conceived the study. $R$ contributed in study design. DM and YL collected data. CSM participated in data analysis and interpretation. DM drafted the manuscript. $R$ and $Y L$ revised the manuscript. All authors read and approved the manuscript for publication.

\section{FUNDING}

None.

\section{DATA AVAILABILITY}

The dataset used and/or analyzed during the current study are available from corresponding author on reasonable request.

\section{ETHICS STATEMENT}

The study protocol was in accordance with ethical procedure (0231/KEPK/IV/2018). All subject was received consent forms.

\section{REFERENCES}

1. Patil S, Rao RS, Majumdar B, Anil S. Clinical Appearance of Oral Candida Infection and Therapeutic Strategies. Frontiers in Microbiology, 2015; 6: 1391-1391. https:// doi.org/10.3389/fmicb.2015.01391

2. Goulart LS, Souza WWRd, Vieira CA, Lima JSd, Olinda RAd, Araujo Cd. Oral colonization by Candida species in HIV-positive patients: association and antifungal susceptibility study. Einstein (Sao Paulo, Brazil), 2018; 16(3): eAO4224-eAO4224. https://doi.org/10.1590/ s1679-45082018ao4224

3. Anwar KP, Malik A, Subhan KH, Profile of candidiasis in HIV infected patients. Iranian journal of microbiology, 2012; 4(4): 204-209.

4. Ribeiro Ribeiro AL, de Alencar Menezes TO, de Melo Alves-Junior S, de Menezes SAF, Marques-da-Silva $\mathrm{SH}$, Rosario Vallinoto AC. Oral carriage of Candida species in HIV-infected patients during highly active antiretroviral therapy (HAART) in Belem, Brazil. Oral Surgery, Oral Medicine, Oral Pathology and Oral Radiology, 2015; 120(1): 29-33. https://doi. org/10.1016/j.000o.2015.03.008

5. Lyu X, Zhao C, Yan Z-M, Hua H, Efficacy of nystatin for the treatment of oral candidiasis: a systematic review and meta-analysis. Drug Design, Development and Therapy, 2016; 10: 1161-1171. https://doi. org/10.2147/DDDT.S100795

6. Patil S, Majumdar B, Sarode SC, Sarode GS, Awan KH, Oropharyngeal Candidosis in HIV-Infected Patients-An Update. Frontiers in Microbiology, 2018; 9: 980-980. https://doi.org/10.3389/fmicb.2018.00980

7. Mungrue K, Sahadool S, Evans R, Boochay S, Ragoobar F, Maharaj K, Green S, Pennerman T, Tayopa O, Assessing the HIV rapid test in the fight against the HIV/AIDS epidemic in Trinidad. HIV/AIDS (Auckland, NZ), 2013; 5: 191-198. https://doi.org/10.2147/HIV. S30432

8. Huang X, Liu X, Chen J, Bao Y, Hou J, Lu X, Xia W, Xia H, Song A, Liu Z, Su B, Chen H, Chen Y, Wu H, Evaluation 
of Blood-Based Antibody Rapid Testing for HIV Early Therapy: A Meta-Analysis of the Evidence. Frontiers in immunology, 2018; 9: 1458-1458. https://doi. org/10.3389/fimmu.2018.01458

9. Byadarahally Raju S, Rajappa S, Isolation and identification of Candida from the oral cavity. ISRN dentistry, 2011; 2011: 487921-487921. https://doi. org/10.5402/2011/487921

10. Coronado-Castellote L, Jiminez-Soriano $Y$, Clinical and microbiological diagnosis of oral candidiasis. Journal of Clinical and Experimental Dentistry, 2013; 5(5):e279-e286. https://doi.org/10.4317/jced.51242

11. Saigal S, Bhargava A, Mehra SK, Dakwala F, Identification of Candida albicans by using different culture medias and its association in potentially malignant and malignant lesions. Contemporary Clinical Dentistry, 2011; 2(3): 188-193. https://doi.org/10.4103/0976$237 X .86454$

12. Nadeem SG, Hakim ST, Kazmi SU, Use of CHROMagar Candida for the presumptive identification of Candida species directly from clinical specimens in resourcelimited settings. The Libyan Journal of Medicine, 2010; 5: 10.3402/ljm.v3405i3400.2144. https://doi. org/10.3402/ljm.v5i0.2144

13. Baradkar V, Mathur M, Kumar S, Hichrom candida agar for identification of Candida species. Indian Journal of Pathology and Microbiology, 2010; 53(1): 93-95. https://doi.org/10.4103/0377-4929.59192

14. Kali A, Srirangaraj S, Charles P, A cost-effective carbohydrate fermentation test for yeast using microtitre plate. Indian Journal of Medical Microbiology, 2015; 33(2): 293. https://doi.org/10.4103/02550857.154884

15. Sahu C, Jain V, Mishra P, Prasad KN, Clinical and laboratory standards institute versus European committee for antimicrobial susceptibility testing guidelines for interpretation of carbapenem antimicrobial susceptibility results for Escherichia coli in urinary tract infection (UTI). Journal of Laboratory Physicians, 2018; 10(3):289-293. https:// doi.org/10.4103/JLP.JLP_176_17

16. Lattif AA, Banerjee U, Prasad R, Biswas A, Wig N, Sharma N, Haque A, Gupta N, Baquer NZ, Mukhopadhyay G, Susceptibility pattern and molecular type of speciesspecific Candida in oropharyngeal lesions of Indian human immunodeficiency virus-positive patients. J. Cli. Microb., 2004; 42(3): 1260-1262. https://doi. org/10.1128/JCM.42.3.1260-1262.2004

17. Ishii H, Matano T, Development of an AIDS vaccine using Sendai virus vectors. Vaccine, 2015; 33(45): 6061-6065. https://doi.org/10.1016/j.vaccine.2015.06.114

18. Kambu $Y$, Waluyo A, Kuntarti K, Umur orang dengan HIV AIDS (ODHA) berhubungan dengan tindakan pencegahan penularan HIV. Jurnal Keperawatan Indonesia, 2016; 19(3): 200-207. https://doi. org/10.7454/jki.v19i3.473

19. Bajomo AS, Ayo-Yusuf OA, Rudolph MJ, Tsotsi NM, Impact of oral lesions among South African adults with HIV/AIDS on oral health-related quality of life. Journal of Dental Sciences, 2013; 8(4): 412-417. https://doi. org/10.1016/j.jds.2013.04.011

20. Oktafiani D, Megasari NLA, Fitriana E, Nasronudin, Lusida MI, Soetjipto, Detection of Human Herpesvirus-8 Antigen In Hiv-Infected Patients In East Java, Indonesia. African Journal of Infectious Diseases, 2018; 12(2): 43-46. https://doi.org/10.21010/ajid.v12i2.7

21. Fauk NK, Kustanti $\mathrm{CY}$, Wulandari R, Damayani AD, Mwanri L, Societal determinants of HIV vulnerability among clients of female commercial sex workers in Indonesia. PloS one, 2018; 13(11): e0207647-e0207647. https://doi.org/10.1371/journal. pone.0207647

22. Prabawanti C, Dijkstra A, Riono P, Hartana G, A survey on HIV-related health-seeking behaviors among transgender individuals in Jakarta, based on the theory of planned behavior. BMC Public Health, 2015; 15: 1138-1138. https://doi.org/10.1186/s12889-0152480-0

23. Altman K, Vanness E, Westergaard RP, Cutaneous manifestations of human immunodeficiency virus: a clinical update. Current Infectious Disease Reports, 2015; 17(3): 464-464. https://doi.org/10.1007/ s11908-015-0464-y

24. Patel PK, Erlandsen JE, Kirkpatrick WR, Berg DK, Westbrook SD, Louden C, Cornell JE, Thompson GR, Vallor AC, Wickes BL, Wiederhold NP, Redding SW, Patterson TF, The Changing Epidemiology of Oropharyngeal Candidiasis in Patients with HIV/AIDS in the Era of Antiretroviral Therapy. AIDS Research and Treatment, 2012; 2012: 262471-262471. https://doi. org/10.1155/2012/262471

25. Sariguzel F, Berk E, Koc A, Sav H, Aydemir G, Evaluation of CHROMagar Candida, VITEK2 YST and VITEK ${ }^{\circledR}$ MS for identification of Candida strains isolated from blood cultures. Infez. Med., 2015; 23: 318-322

26. Mohamadi J, Motaghi M, Panahi J, Havasian MR, Delpisheh A, Azizian M, Pakzad I, Anti-fungal resistance in candida isolated from oral and diaper rash candidiasis in neonates. Bioinformation, 2014; 10(11): 667-670. https://doi.org/10.6026/97320630010667

27. Moges B, Bitew A, Shewaamare A, Spectrum and the In vitro Antifungal Susceptibility Pattern of Yeast Isolates in Ethiopian HIV Patients with Oropharyngeal Candidiasis. International Journal of Microbiology, 2016; 2016: 8. https://doi.org/10.1155/2016/3037817 